\title{
Changes in the Structure of Synapses Associated with Learning ${ }^{1}$
}

\author{
G. HORN, ${ }^{*}, 2$ P. BRADLEY,‡ AND B. J. MCCABE* \\ * Department of Zoology, University of Cambridge, Downing Street, Cambridge CB2 3EJ, and $\ddagger$ Department of Anatomy, University of \\ Newcastle upon Tyne, NE2 4HH, United Kingdom
}

\begin{abstract}
Two experiments were conducted to investigate the effects of training on a region of the chick brain known to be critically involved in imprinting, the intermediate and medial extent of the hyperstriatum ventrale (IMHV). In the first experiment, three groups of chicks were used: (i) dark-reared $(n=9)$, (ii) trained for $20 \mathrm{~min}(n=17)$, and (iii) trained for $140 \mathrm{~min}(n=$ 7). Chicks were trained by exposing them when they were approximately $21 \mathrm{hr}$ old to a flashing red light. Chicks were killed when they were approximately $30 \mathrm{hr}$ old and blocks of tissue were removed from the right and left IMHV. Stereological techniques were used to measure from electron micrographs the numerical density of dendritic spine and shaft synapses and the length of the postsynaptic density of these synaptic junctions. There was a significant effect of training only in the left IMHV and on only one measure, the overall mean length of the postsynaptic density of spine synapses, $\overline{S P}_{L}$. This measure was significantly greater by $17.2 \%$ in chicks trained for $\mathbf{1 4 0}$ min than in dark-reared controls. There was no significant effect of training for $20 \mathrm{~min}$.

In the second experiment one group of chicks $(n=15)$ was exposed to a rotating red box for a total of $3 \mathrm{hr}$. Another group of chicks was dark-reared $(n=15)$. The chicks were killed when they were approximately $\mathbf{4 6} \mathrm{hr}$ old. Samples from the hyperstriatum accessorium and IMHV of the right and left sides were analyzed. Training was associated with a significant change, an increase, only of $\overrightarrow{S P}_{L}$ in the left IMHV. There was a significant correlation between the extent to which chicks ran toward the training object and values of $\overline{S P}_{L}$ in this region of the brain. The results of the two experiments are discussed in relation to the role of IMHV in the learning process of imprinting.
\end{abstract}

When visually naive domestic chicks are trained by exposing them for an adequate length of time to one of a wide variety of objects, the chicks subsequently approach that object and avoid others. The process by which young chicks learn to recognize an object in this way is known as imprinting (see Sluckin, 1972). Changes in the incorporation of radioactive uracil into RNA in the forebrain were found to be closely related to this process (see Horn et al., 1973; Horn, 1981). Incorporation was found to be higher in a limited part of the cerebral hemispheres of trained chicks when compared with that in controls (Horn et al., 1979). The region implicated lay within the hyperstriatum ventrale (see

Received October 26, 1984; Revised May 22, 1985;

Accepted June 4, 1985

${ }^{1}$ We are grateful to $P$. Altham for advice on statistical problems, to $B$. Fuller and W. Nix for technical assistance, and to the Science and Engineering Research Council and the Medical Research Council for financial support.

${ }^{2}$ To whom correspondence should be addressed.
Fig. 1A). The incorporation of radioactive uracil was higher in the intermediate extent of the hyperstriatum ventrale, close to the midline, a region referred to as IMHV (see Fig. 1B). This region was also implicated in the imprinting process by Kohsaka et al. (1979) using the $\left[{ }^{14} \mathrm{C}\right]$-2-deoxyglucose technique.

When bilateral lesions were placed in IMHV and the chicks were subsequently trained they failed to acquire a preference for the training object, a rotating, flashing red box (McCabe et al., 1981). When bilateral lesions were placed in the area shortly after training, retention was severely impaired. This effect was not obtained by lesions placed in two other regions of the forebrain. Chicks with bilateral lesions of IMHV showed no visuomotor impairment as judged by a number of criteria. Furthermore, these chicks were able to discriminate between two visual patterns when they were rewarded for making the correct choice (McCabe et al., 1982). The lesion thus dissociated the memory necessary for recognition from the memory necessary for associative leaning (see also Johnson and Horn, 1985). These two forms of memory may be dissociated in human diencephalic and medial temporal lobe amnesias (for reviews see Weiskrantz, 1982; Zangwill, 1983), and an apparently similar dissociation may be achieved by appropriately placed lesions in rhesus and cynomolgus monkeys (Gaffan, 1974; Aggleton and Mishkin, 1983a, b; Zola-Morgan and Squire, 1984; Mahut, 1985). The effects of lesions to IMHV together with the results of biochemical (Horn et al., 1979; Davies et al., 1985) and electrophysiological studies (Payne and Horn, 1982, 1984) suggest that IMHV is critically involved in recognition memory.

Changes in neuronal connections have often been postulated to underlie information storage in the brain (Tanzi, 1893; Ramón y Cajal, 1911; Konorski, 1948; Hebb, 1949). The present study was therefore undertaken to enquire whether training is associated with changes in synapses within IMHV. Two training regimens were used in this study. In the first a moving horizontal red bar of light was presented in such a way as to appear to flash. This stimulus is a highly effective imprinting stimulus (Bateson, 1979). The second regimen, employing a different training stimulus, was used to enable comparisons to be made with a series of experiments which had been designed to investigate some electrophysiological consequences of imprinting (Brown and Horn, 1979; Payne et al., 1984; Payne and Horn, 1984). In these experiments microelectrodes were used to record the activity of neurons in IMHV and in the hyperstriatum accessorium, a visual projection area (Hunt and Webster, 1972; Karten et al., 1973; Miceli et al., 1975, 1979). We have therefore enquired whether any changes in the structure of synapses can be detected in these two brain regions in chicks subjected to a training regimen similar to that used in the electrophysiological experiments.

Preliminary accounts of some of these results have been published (Bradley and Horn, 1979; Bradley et al., 1979, 1981). 


\section{Materials and Methods}

Experiment 1. A total of 33 domestic chicks (Ross 1) were used. Details of the methods for incubation, hatching, and handling are described elsewhere (Bateson et al., 1975). The chicks were derived from two batches of eggs. The first batch contributed 14 chicks to the experiment. The age at which chicks hatch is accurate to $\pm 2 \mathrm{hr}$; all statements about age have this range of variation. The chicks were reared in darkness and in social isolation until they were approximately $21 \mathrm{hr}$ old. The chicks were then "primed" (Bateson and Wainwright, 1972; Cherfas, 1978) by being exposed to diffuse illumination provided by a $60 . \mathrm{W}$ bulb suspended $1.5 \mathrm{~m}$ above the incubator. Priming lasted for $0.5 \mathrm{hr}$ after which the chicks remained in the dark incubator for an additional $0.5 \mathrm{hr}$. The chicks were then placed singly in running wheels. Through the curved mesh floor of the wheel on which the chick walked it could see the training stimulus $40 \mathrm{~cm}$ in front of the wheel. The stimulus was a horizontal slit of red light $2 \mathrm{~cm}$ high and moving upwards at $47 \mathrm{~cm} / \mathrm{sec}$ in a window $10 \mathrm{~cm}$ wide $\times 15 \mathrm{~cm}$ deep (for details see Bateson, 1979; Horn et al., 1979). The rate of movement was such that the stimulus presented four separate upward-moving slits per second. This flash rate has been found optimally attractive to day-old chicks (Gottlieb and Simner, 1969; Simner, 1973). Above the flashing light was a loudspeaker which emitted the natural maternal call of the domestic hen at an average intensity of $65 \mathrm{~dB}$ (reference, $20 \mu \mathrm{Nm}^{-2}$ ). The running wheel and the training stimulus were housed in a temperature-controlled cabinet. As a chick attempted to approach the training stimulus the running wheel rotated. The number of rotations made by the wheel was recorded and used as a measure of approach activity. All chicks in this batch were exposed to the training stimulus for $20 \mathrm{~min}$. In order to select chicks which were behaviorally responsive, inactive chicks were discarded. Active chicks were matched in pairs and one member ("undertrained") of the pair returned to the dark incubator where it remained until it was killed. The other member ("overtrained") of the pair was trained for another $120 \mathrm{~min}$ in three 40-min sessions interspersed with periods of $40 \mathrm{~min}$ which were spent in the dark incubator. After the final session the chick was returned to the dark incubator for $3 \mathrm{hr}$ At the end of this time the chicks were approximately $30 \mathrm{hr}$ old. The second batch of 19 chicks was reared in darkness and divided into two groups. Ten chicks were trained for $20 \mathrm{~min}$ as described above. The remaining 9 "dark reared" chicks were individually housed in the dark incubator throughout the experiment

Immediately before the chicks were killed they were given a code number and all subsequent procedures were performed "blind." The code was only broken after all measurements had been made (see below). Each chick was deeply anesthetized when it was approximately $30 \mathrm{hr}$ old and was perfused with $0.1 \mathrm{M}$ phosphate buffer, $\mathrm{pH} 7.4$, followed by fixative consisting of $2 \%$ paraformaldehyde/2\% glutaraldehyde in the same buffer. The chick was decapitated, the head was placed in a stereotaxic instrument, and a $1-\mathrm{mm}$. thick coronal section was cut in the plane illustrated in Figure $1 B$. The section was cut under stereotaxic control. A 1-mm square block was then removed from the right and left IMHV and prepared for electron microscopy.

The sampling technique used to obtain micrographs from each block has been described elsewhere (Bradley et al., 1981). The micrographs were printed to a final magnification of $\times 22,200$. Point counting techniques (Weibel and Bolender, 1973) were used to measure the volume occupied by cell bodies. This measure was used in the derivation of the numerical density of synapses (see below). The measure did not change significantly in any analysis. Synapses were defined by the presence of synaptic vesicles in conjunction with a synaptic cleft and a postsynaptic density (see Fig. 2). A profile was identified as a spine if the connecting stalk with a dendrite was visible with or without the presence of a synaptic density. Profiles without a stalk but possessing a synaptic density were identified as spines using the criteria given by Gray (1959). The mean caliper diameter, subsequently referred to as the mean length of the postsynaptic density, was estimated by the method of intersection counting (Weibel, 1969; Mayhew, 1979). The mean lengths of the postsynaptic densities of spine synapses $\left(\overline{S P}_{L}\right)$ were treated separately from length measurements of synapses on dendritic shafts. The numerical densities per unit volume of synapses on spines and on dendritic shafts, respectively, were calculated from the expression (see Weibel, 1979; Colonnier and Beaulieu, 1985):

$$
N_{v}=\frac{N_{A}}{\overline{P S D}}
$$

when $N_{V}$ is the number of synapses per unit volume of neuropil, $N_{A}$ is the number of synaptic profiles per unit area of neuropil, and $\overline{P S D}$ is the mean length of the postsynaptic density, either of shaft or of spine synapses. The
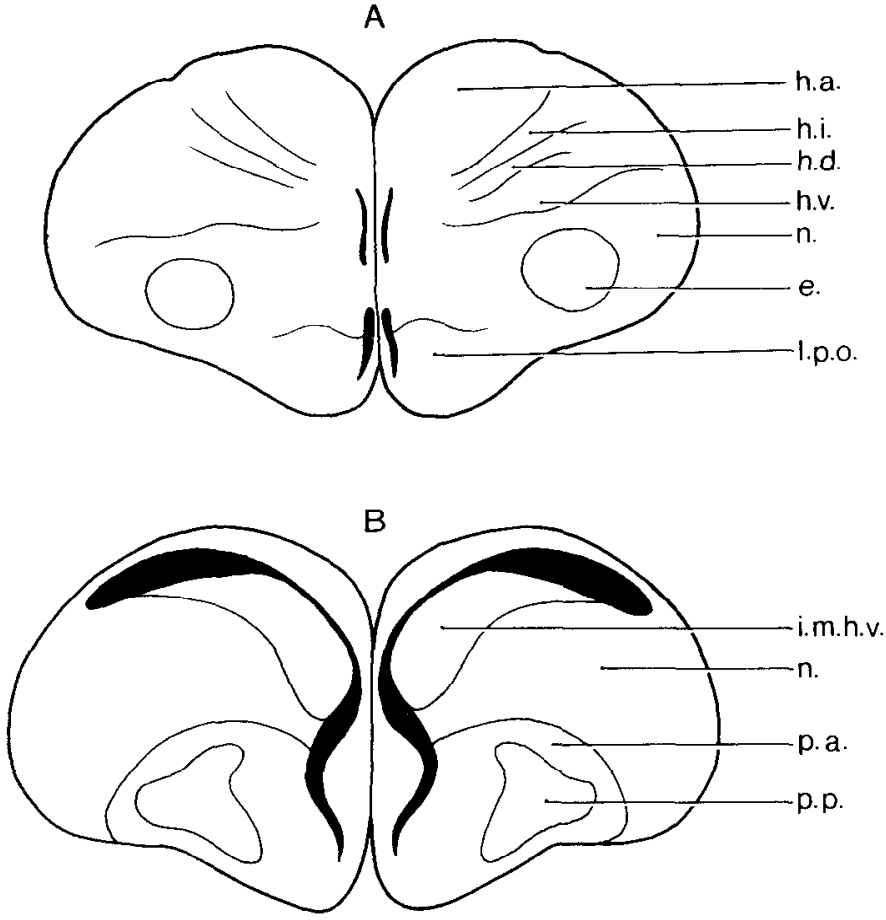

$5 \mathrm{~mm}$

Figure 1. Diagrams of chick brain showing planes from which $1-\mathrm{mm}$ coronal sections were cut under stereotaxic control. $A$, Plane from which blocks of the right and left hyperstriatum accessorium were removed. $B$, Plane from which blocks of right and left IMHV were removed. The solid areas represent ventricles. e. ectostriatum; $h . a_{\text {. }}$ hyperstriatum accessorium; $h . d$. , hyperstriatum dorsale; h.i, hyperstriatum intercalatus; $h . v$., hyperstriatum ventrale; i.m.h.v., intermediate and medial part of hyperstriatum ventrale (IMHV): 1.p.o., lobus paraolfactorius; $n$., neostriatum; p.a., paleostriatum augmentatum; p.p., paleostriatum primitivum.

numerical densities were expressed relative to the volume of neuropil not occupied by cell bodies, since axosomatic synapses were extremely rare. Since the preliminary investigation (Bradley et al., 1981) had failed to implicate in imprinling the areas of microyraph occupied, respectively, by presynaptic boutons and dendritic spines, these features of the micrographs were not studied in the extended sample of chicks.

For each structure sampled each chick contributed one mean value for the left IMHV and one for the right IMHV. Only these values were used for statistical analysis. Micrographs from the overtrained and undertrained chicks of the pair were shuffled at least twice, and all measurements were made without knowledge of either the brain hemisphere or the behavioral experi. ence of the chick.

In batch 1, chicks were trained for 20 min or for $140 \mathrm{~min}$; in batch 2 they were trained for $20 \mathrm{~min}$ or were dark-reared. In order to exclude "betweenbatch" variation, and to peririt data from dark-reared chicks lo be compared with data from overtrained chicks, each data value was standardized by subtracting from it the mean of the 20-min group in the same batch (see Cochran and Cox, 1957). Data were then subjected to an analysis of variance to compare the dark-reared, undertrained, and overtrained groups. Mean values for dark-reared control chicks are given. Data for trained chicks are given only where they differ significantly from those of controls.

Experiment 2. Thirty chicks were used in this experiment. The chicks were hatched and reared in darkness. Approximately $21 \mathrm{hr}$ after hatching, 15 chicks were primed for $0.5 \mathrm{hr}$ and then remained in darkness for another 0.5 $\mathrm{hr}$. Each of these chicks was then placed in a running wheel and exposed to a rotating, flashing red box (McCabe et al., 1981) for $1 \mathrm{hr}$ when they were approximately $22 \mathrm{hr}$ old and for $1 \mathrm{hr}$ when they were approximately $24 \mathrm{hr}$ old. The rotating red box is an effective imprinting stimulus (McCabe et al., 1982; Horn and McCabe, 1984). At the end of this period the chicks were returned to the dark incubator where they remained until they were approximately $42 \mathrm{hr}$ old. They were then placed in running wheels and exposed to the red box for another $1 \mathrm{hr}$. These chicks were again returned to the 

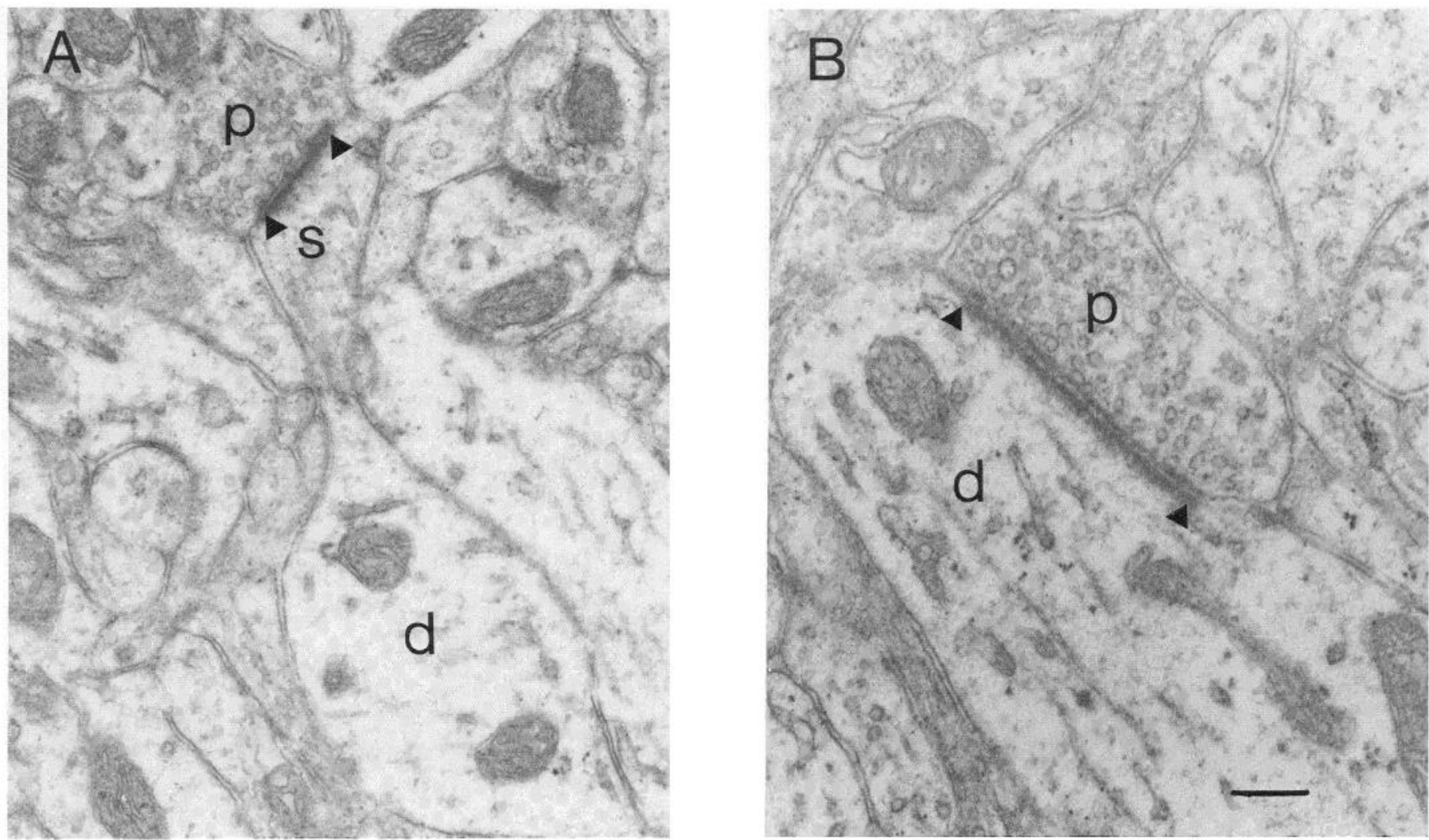

Figure 2. Electron micrographs of spine $(A)$ and shaft $(B)$ synapses in IMHV. The thickened membrane between the arrowheads is the postsynaptic density. $d$, shaft of dendrite; $p$, presynaptic bouton; $s$, spine connected to the shaft of a dendrite. Scale bar $=200 \mathrm{~nm}$.

incubator and remained in the dark for an additional $3 \mathrm{hr}$. The number of rotations of the running wheel during the 3 -hr training period was recorded as described above. The remaining 15 "dark-reared" chicks received no visual experience at all, but stayed in individual compartments within the dark incubator. All chicks were given a code number, and all subsequent procedures were performed "blind." When the chicks were approximately $46 \mathrm{hr}$ old they were killed as described for experiment 1 . Coronal sections were removed under stereotaxic control from the plane illustrated in Figure $1 B$, and blocks of the right and left IMHV were prepared as described above. Blocks from the right and left hyperstriatum accessorium were prepared from coronal sections cut in the plane illustrated in Figure $1 \mathrm{~A}$. The stereotaxic coordinates of both planes are given by Brown and Horn (1979). In addition to the synaptic structures sampled in experiment 1 , an estimate was made of mean spine area (James, 1977) since the percentage of volume occupied by spines had previously been shown to vary with visual experience (Bradley and Horn, 1979). As in experiment 1, the volume occupied by cell bodies did not change significantly in any analysis.

All data were subjected to an analysis of variance, the factors being experimental treatment (dark-reared or trained), brain region (IMHV or hyperstriatum accessorium), and side (left or right). Each morphological variable was plotted against training activity, and product-moment correlation coefficients were calculated.

\section{Results}

\section{Experiment 1}

Data for dark-reared controls are given in Table I. The effects of training were examined by comparing standardized measures for trained chicks with corresponding measures for the dark-reared birds. Training chicks for 20 min or for $140 \mathrm{~min}$ had no significant effect on the numerical density of spine or shaft synapses or on the length of the postsynaptic density of shaft synapses. There was, however, a significant interaction between hemisphere and training condition for mean length, $\overline{S P}_{L}$, of the postsynaptic density of spine synapses $\left(F_{2,27}=4.98 ; p<0.025\right)$. Accordingly, this measure was analyzed separately for each hemisphere.
There was a significant effect of training on $\overline{S P}_{L}$ of the left IMHV $\left(F_{2,30}=5.17 ; p<0.025\right)$. For dark-reared chicks the mean $\overline{S P}_{L}$ was $286.0 \pm 12.24$ (SE) $\mathrm{nm}$. This mean was significantly less $(\mathrm{t}=2.77$, $p<0.01$ ) than that of the overtrained birds and not significantly different from that of the undertrained birds. $\overline{S P}_{L}$ was significantly greater in overtrained birds than in undertrained birds $(t=3.02, p$ $<0.01$ ) (Fig. 3).

The mean value of $\overline{S P}_{L}$ for the right IMHV of dark-reared chicks was $294.4 \pm 7.18 \mathrm{~nm}$. There was no significant effect of training on this value (Fig. 3 ).

\section{Experiment 2}

Effects of training. The mean values of the various measures of synapse morphology for dark-reared controls are given in Table II. The data are set out according to brain region and hemisphere. Analysis of variance revealed that the only measure significantly affected by training was $\overline{S P}_{L}\left(F_{1,28}=4.76, p<0.05\right)$. For the left $\mathrm{IMHV}, \overline{S P}_{L}$ in trained chicks was significantly greater than in darkreared chicks (Fig. 4). There were no significant differences between

TABLE I

Experiment 1: Measurements of synapses in IMHV of dark-reared chicks

\begin{tabular}{lll}
\hline & Left Hemisphere & Right Hemisphere \\
\hline $\begin{array}{l}\text { Numerical density } / 100 \mu \mathrm{m}^{3} \\
\text { Spine synapses }\end{array}$ & $11.86 \pm 1.11^{\mathrm{a}}$ & $12.62 \pm 0.78$ \\
$\quad$ Shaft synapses & $10.42 \pm 0.65$ & $10.38 \pm 0.88$ \\
$\begin{array}{l}\text { Length of postsynaptic } \\
\quad \text { density (nm) }\end{array}$ & \\
$\quad$ Spine synapses & $286.0 \pm 12.24$ & $294.4 \pm 7.18$ \\
Shaft synapses & $333.4 \pm 12.73$ & $340.7 \pm 19.93$ \\
\hline
\end{tabular}

${ }^{a}$ Values are means $\pm \mathrm{SE}$ 
A$$
H_{t} \|
$$

B

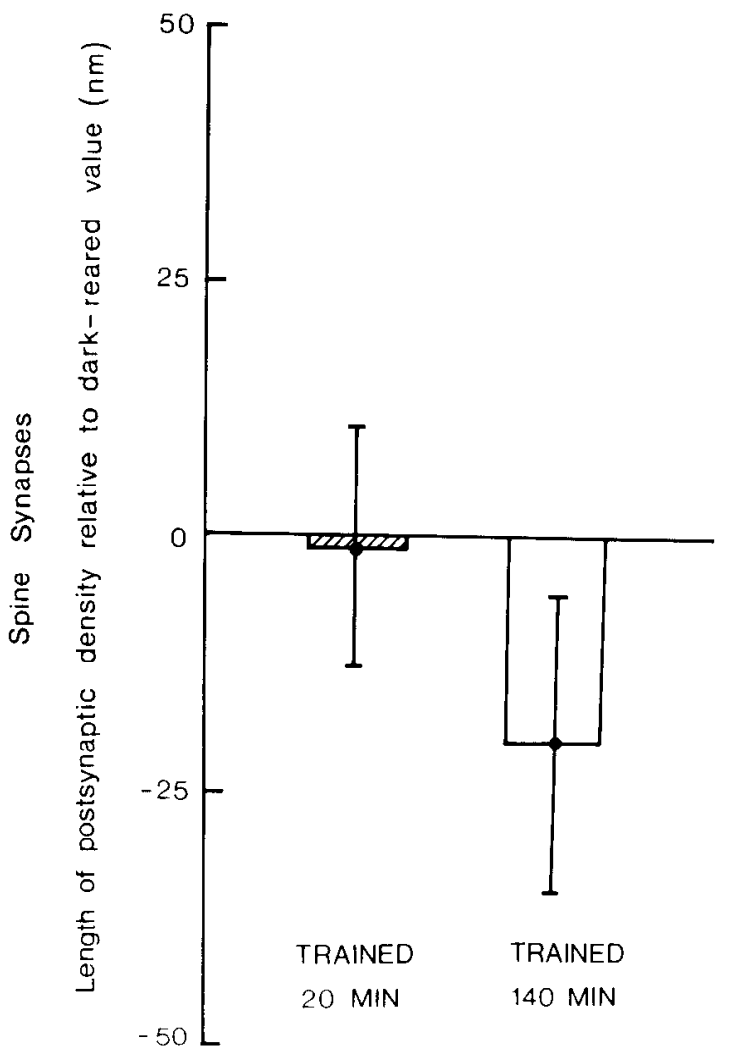

trained and untrained chicks in the right IMHV or in either side of the hyperstriatum accessorium.

The relationship between approach activity during training (Table III) and the length of the postsynaptic density of spine synapses was examined. Correlation coefficients were calculated using $\overline{S P}_{L}$ and approach counts as variables. For the left IMHV the correlation between $\overline{S p}_{L}$ and approach counts made during the first hour of training was significant $(r=0.52, d f=13, p<0.05)$. The correlation was not significant when approach counts during the second and third hour of training were used as variables $(r=0.12$ and $r=0.23$, respeclively). None of the corresponding correlations between approach activity and $\overline{S P}_{L}$ for the right IMHV or for the hyperstriatum accessorium were significant.

IMHV and hyperstriatum accessorium compared. The two brain regions were compared in dark-reared chicks (see Table II). Hyperstriatum accessorium differed significantly from IMHV in respect to mean area of dendritic spine profiles $\left(F_{1,35}=86.66, p<0.001\right)$, numerical density of shaft synapses $\left(F_{1,35}=147.5, p<0.001\right)$, and length of postsynaptic density of shaft synapses $\left(F_{1,35}=20.21, p\right.$ $<0.001$ ).

Age changes in synapse morphology in IMHV. At the time the dark-reared chicks were perfused they were approxiamtely $30 \mathrm{hr}$ old in experiment 1 and approximately $46 \mathrm{hr}$ old in experiment 2 . The data (Tables I and II) suggest that statistically significant changes occurred in several measures of synapse structure over this time (unpaired $t$ tests; $\rho<0.05$ in all cases). $\overline{S P}_{L}$ increased significantly with age in both the left and right IMHV. There was a similar increase in the length of the postsynaptic density of shaft synapses. However, the numerical density of shaft synapses decreased significantly with age in $\mathrm{MH}$ V of each side.

\section{Discussion}

In the preliminary report of the effects of imprinting on the morphology of synapses in IMHV only overtrained and undertrained chicks were used (Bradley et al., 1981). In that report, data for the length of the postsynaptic density had been obtained by combining measures for shaft and spine synaptic junctions. Further training was associated with a significant increase in the length of the postsynaptic density of the junctions in the left IMHV. The slight decrease in length of these junctions in the right IMHV was not statistically significant. In the present study we have established that: (i) 20 min of training was not associated with a significant change in the length of the postsynaptic density compared with that of dark-reared controls, (ii) further training was associated with an increase in the length of the postsynaptic density on dendritic spine synapses in the left IMHV, whereas this measure for shaft synapses was not significantly affected by overtraining, and (iii) there were no significant changes associated with training in the length of spine or shaft synapses in the right IMHV.

Relative to dark-reared controls the mean increase of $49.2 \pm 17.7$ $\mathrm{nm}$ in the length of spine junctions in the left IMHV represents a $17.2 \%$ change. If the synaptic junction is circular, then its diameter is a simple function of the estimated junction length (Weibel and Bolender, 1973). Accordingly, this increase in length would correspond to an increase in area of approximately $37 \%$.

Chicks which have formed an attachment to the training object prefer it to a novel object. The strength of this preference provides a measure of the strength of imprinting (Sluckin, 1972). When chicks were exposed for $21 \mathrm{~min}$ to the training stimulus used in experiment 1, they did not prefer it to a novel object (Bateson, 1979). Although the chicks' preferences were not tested in the present study, it is

Figure 3. Experiment 1: Length of postsynaptic density of spine synapses. $A$, Left IMHV; $B$, right IMHV. Data for the 20-min and 140-min trained groups are shown relative to those of dark-reared controls shown as 0 . The mean difference between this value and the values for undertrained (hatched bars) and overtrained chicks (open bars), respectively, are given. The error bar associated with each mean is the standard error of the difference between that mean and the dark-reared value. 
TABLE ॥

Experiment 2: Synapse measurements for dark-reared chicks given according to brain region and hemisphere

\begin{tabular}{|c|c|c|c|c|}
\hline & \multicolumn{2}{|c|}{ IMHV } & \multicolumn{2}{|c|}{ Hyperstriatum Accessorium } \\
\hline & $\begin{array}{l}\text { Left } \\
\text { Hemisphere }\end{array}$ & $\begin{array}{c}\text { Right } \\
\text { Hemisphere }\end{array}$ & $\begin{array}{l}\text { Left } \\
\text { Hemisphere }\end{array}$ & $\begin{array}{c}\text { Right } \\
\text { Hemisphere }\end{array}$ \\
\hline \multicolumn{5}{|l|}{ Numerical density $/ 100 \mu \mathrm{m}^{3}$} \\
\hline Shaft synapses & $7.03 \pm 0.66$ & $6.58 \pm 0.36$ & $15.96 \pm 1.02$ & $13.52 \pm 0.92$ \\
\hline \multicolumn{5}{|c|}{$\begin{array}{l}\text { Length of postsynaptic density } \\
\qquad(\mathrm{nm})\end{array}$} \\
\hline Area of spine profile $\left(\mu \mathrm{m}^{2}\right)$ & $0.21 \pm 0.01$ & $0.20 \pm 0.01$ & $0.27 \pm 0.01$ & $0.27 \pm 0.01$ \\
\hline
\end{tabular}

${ }^{2}$ Values are means $\pm \mathrm{SE}$

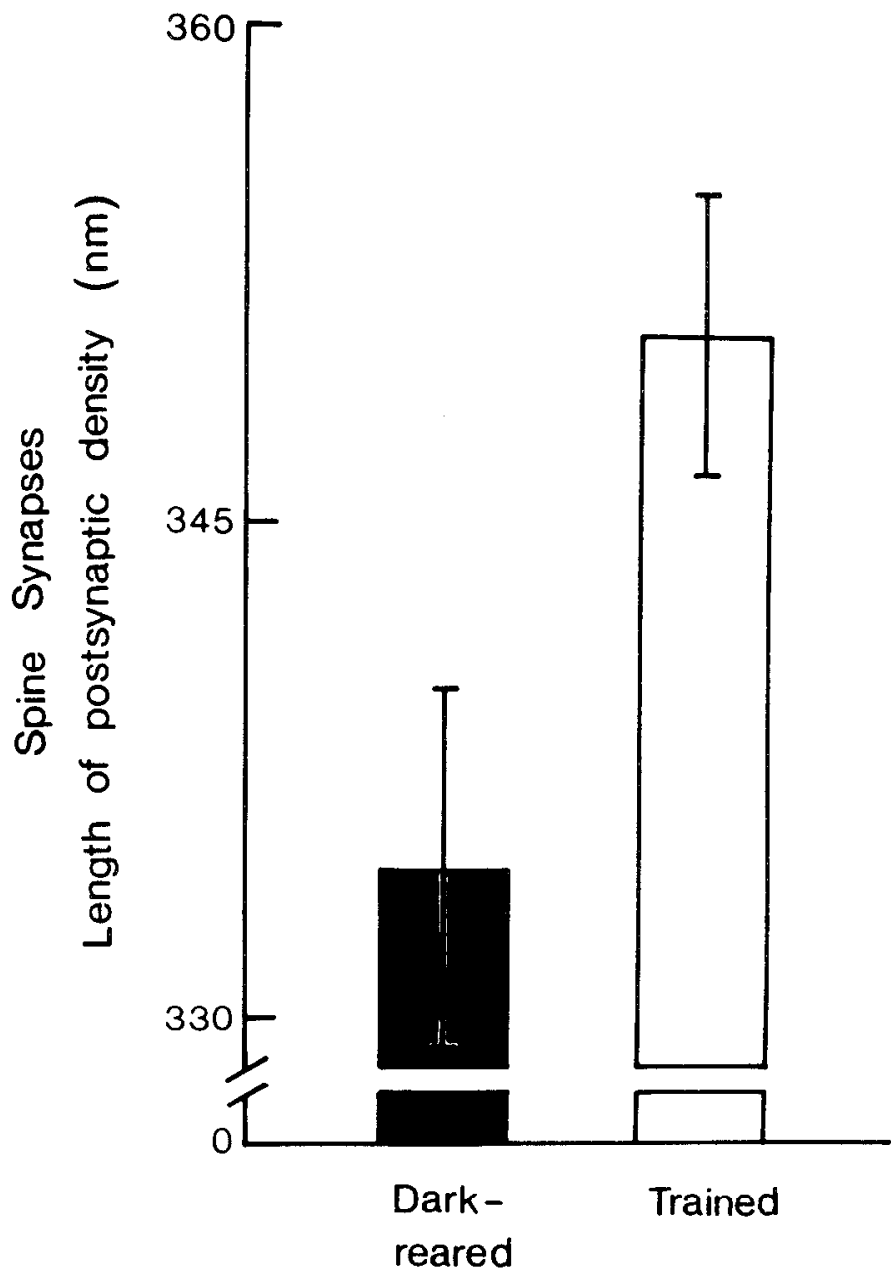

Figure 4. Experiment 2: Spine synapses in the left IMHV-Effects of exposing chicks for a total of $3 \mathrm{hr}$ to a rotating red box. The bars represent the mean $( \pm \mathrm{SE}$ ) length of the postsynaptic junction for dark-reared (solid bars) and trained chicks (open bars). Training was associated with a significant increase in the length of the postsynaptic density $(t=2.32, p<$ $0.05)$.

reasonable to suppose that the undertrained chicks had not formed a preference for the training object. There were no changes in any measure of synapse morphology in the left or right IMHV region of these birds compared with their dark-reared controls, even though the undertrained chicks had been primed and had been exposed to the training stimulus for $20 \mathrm{~min}$. In contrast, chicks exposed to the training stimulus for 81 min showed a clear preference for it over a novel stimulus (Bateson, 1979). The overtrained birds of experiment
TABLF II

Experiment 2: Approach counts in each hour of training for chicks exposed to the red box

\begin{tabular}{lccc}
\hline & First Hour & Second Hour & Third Hour \\
\hline $\begin{array}{l}\text { Time of beginning of } \\
\text { training (hr after } \\
\text { hatching) }\end{array}$ & 22 & 24 & 42 \\
Approach counts & $427.5 \pm 77.38^{a}$ & $516.6 \pm 86.04$ & $664.3 \pm 95.03$ \\
\hline
\end{tabular}

${ }^{2}$ Values are means $\pm \mathrm{SE}$.

1 were exposed to the training stimulus well in excess of $81 \mathrm{~min}$; thus, it may be inferred that they had formed a preference for it. The associated morphological change in these chicks was selective both for side and for synapse type. A similar morphological consequence of training was found in experiment 2 even though the training objcct and training schedule were different from those of experiment 1. Furthermore, in experiment 2 there was a correlation between approach activity during the first hour of training and the length of the postsynaptic density of spines in the left MHV. Approach activity is correlated with preference for the training object (Bateson and Jaeckel, 1974); the more chicks run toward this object the more they appear to learn about it. This effect is probably asymptotic (Bateson et al., 1973), so that the chicks may have learned more about the object in the first hour of training than they did in the second and third hours.

In spite of the consistency between the expectations based on the different training schedules and the observed synaptic changes in $\mathrm{MHV}$, it remains possible that these changes have little to do with learning. They might be a consequence of some side-effect of the training procedure and might be attributable, for example, to differences in the amount chicks moved during training. Movement per se is unlikely, however, to be the critical factor. One reason is that only approach activity during the first hour of training was correlated with the length of spine synaptic junctions. The corresponding correlation using the approach during the second and third hours of training fell far short of statistical significance. Approach in the first hour of training was, if anything, less than the other two hours. Nevertheless, the general argument would be difficult to refute if the reason for implicating $\mathrm{IMHV}$ in the learning process rested solely on the synaptic changes found there after training. This is not, however, the case. The studies which lead to the localization of IMHV had excluded locomotor and sensory activity and a variety of other sideeffects of training as factors responsible for certain biochemical changes which are associated with imprinting (see Horn et al., 1973). These and other data (see Horn, 1981, 1985; Kossut and Rose 1984; Stewart et al., 1984; Takamatsu and Tsukada, 1985), including the results of lesion studies (see the introduction), strongly implicate $\mathrm{MHV}$ in the process of information storage.

Changes in the size of presynaptic boutons (Hebb, 1949) and of dendritic spines (Rall and Rinzel, 1971; Rall, 1974) have been 
postulaled to underlie memory. There were no effects of overtraining on the area of tissue occupied by these structures in either the left or the right IMHV (Bradley et al., 1981). However, in that study the samples of dendritic spines which were measured were predominantly of the spine head. Changes in the diameter of the spine neck could exert a profound influence on the functional "weight" of a synapse (Chang, 1952; Rall and Rinzel, 1971; Rall, 1974; Koch et al., 1982). Such changes, if small and selective for particular kinds of spine (Rall, 1974; Koch et al., 1982), might not have been detected by the measures used by Bradley et al. (1981). Similarly, the absence of an effect of overtraining on the numerical density of either type of synapse does not exclude the possibility that the absolute number of synapses present in IMHV may be affected by training. Such an increase might be achieved if training was associated with an increase in the branching of dendrites, provided that the newly formed branches maintaince the same density of synapses as in the undertrained and dark-reared chicks. Although we do not wish to exclude these possibilities, it is worth emphasizing the positive findings of the present study, namely, that a change in length of the postsynaptic density was identified in a region which is critical for information storage. The region of the postsynaptic density may be the site of high receptor density (Jacob and Lenz, 1979; Cohen, 1980). If so, an increase in the area of this region of membrane specialization may represent an increase in the number of ligandbinding sites. It is possible (Horn, 1962) that such a change, by increasing the effectiveness of transmission, would functionally weight the synapse and hence (Hebb, 1949) form a basis of memory.

The change in length of the postsynaptic density could occur through the addition of new membrane to, or by the modification/ replacement of, nonsynaptic membrane in the spine head. If the former process were involved, the increase in surface area would be expected to lead to an increase in the volume of dendritic spines. Such an increase in volume did not occur (Bradley et al., 1981). It seems reasonable, therefore, to suppose that the increase in length of the postsynaptic density was achieved either by a modification of nonsynaptic membrane or by its substitution with synaptic membrane.

Approach counts during the first hour of training were correlated with $\overline{S P}_{L}$ in the left IMHV. This training period took place approximately $24 \mathrm{hr}$ before the chicks were killed; thus, the correlation is a remarkable one. It is, however, no less remarkable than the findings of an electrophysiological analysis of spontaneous impulse activity in these two regions (Payne and Horn, 1982, 1984). In these studies chicks were treated in the same way as the trained chicks in experiment 2. After the final hour of training the chicks were anesthetized and the discharge of units was recorded. Because the evidence of the preliminary electron microscopy study pointed to a role of the left IMHV in imprinting, recordings were made in this side of the brain only. The mean firing rate from three or more recording sites was calculated for the left IMHV. There was a significant correlation between approach counts in the first hour of training and spontaneous impulse activity in this region (Payne and Horn, 1984).

The correlation between approach counts and $\overline{S P}_{L}$ was positive: the more chicks ran toward the training stimulus the longer was the postsynaptic density of spine synapses. If these synapses are excitatory, as has been suggested (Gray, 1959; Eccles, 1964), and contribute to the generation of spontaneous impulse activity in the postsynaptic cells, then the longer the junction the greater would be the influence of the presynaptic fiber on the discharge of the postsynaptic cell. Hence, even if the activity of the presynaptic fiber is held constant, the longer the spine junction the more efficiently would the activity of the presynaptic fiber be transmitted to the postsynaptic neuron. Accordingly, if approach activity is positively correlated with $\overline{S P}_{L}$, approach should also be positively correlated with mean spontaneous firing rate. However, approach activity was negatively correlated with spontaneous firing rate (Payne and Horn, 1984). Thus, the more strongly chicks approached the training object the longer was $\overline{S P}_{L}$ but the lower was the mean firing rate of neurons.
This reversal in sign of the correlation could be achieved if an inhibitory neuron were interposed between the cell with the modifiable synapse and the recorded cell.

The evidence of an asymmetry in the morphological response of left and right IMHV to overtraining suggests that the two regions may play different roles in the imprinting process. The suggestion is supported by evidence provided by lesioning the right and left IMHV (Cipolla-Neto et al., 1982; Horn et al., 1983). Hemispheric asymmetries in the control of behavior in domestic chicks (Howard et al., 1980; Andrew and Brennan, 1983) and in certain passerine birds (see Nottebohm, 1980) is now well established, so that the finding of such asymmetry in imprinting, although originally unanticipated, is not, perhaps, surprising.

There were no significant effects of training on any measure of synapse morphology in the hyperstriatum accessorium. However, in a preliminary account of the morphology of synapses in the hyper striatum accessorium Bradley and Horn (1979) found that the percentage volume occupied by spines was significantly increased in the trained chicks compared with dark-reared controls. In that study there were five chicks in each treatment group and the difference was significant with a probability of less than 0.05 that the results had occurred by chance. It is possible that this result had occurred by chance since mean spine area was not significantly affected by experience in the larger sample used in the present study. There may, however, be other factors that might influence the likelihood of detecting a morphological change in the hyperstriatum accessorium as a consequence of training. Training affects both the responsiveness to visual stimulation and the spontaneous activity of units in this region (Payne et al., 1984; Payne and Horn, 1984). These effects were restricted to chicks which possessed a visually responsive lamina deep to the hyperstriatum accessorium. When data from chicks with and without this lamina were pooled, there were no consistent effects of training either on spontaneous activity or on visual responsiveness. If the visual experience of training in experiment 2 is associated with morphological changes in the hyperstriatum accessorium, these would be predicted on the basis of the physiological studies only for chicks with a visually responsive lamina. These chicks were not identified in the present study. Approximately half the chicks in a batch possess the lamina (Payne et al., 1984). Hence, any effect of training might have been diluted by the contribution of data from chicks which did not possess the lamina.

At the time the chicks were perfused, those in experiment 2 were approximately $16 \mathrm{hr}$ older than those in experiment 1 . Several measures of synapse structure in IMHV had changed in the intervening period as evidenced by a direct comparison of the darkreared birds in each group. Although the results of this comparison should be treated with caution, because age and batch effects were confounded, other evidence suggests that changes in the structure of synapses are occurring in IMHV in the first few days after hatching (Bradley, 1985). In the hyperstriatum accessorium, the adult distribution of synapses on dendritic spines and shafts is achieved during this time (Corner et al., 1977). The adult length of synaptic junctions prepared from whole forebrains is also achieved by the first week after hatching (Rostas et al., 1984). The evidence suggests, therefore, that during the period in which imprinting takes place IMHV is in a labile state.

In the 46-hr-old dark-reared chicks of experiment 2, more shaft synapses wore prosent per unit volume in the hyperstriatum acces sorium than in IMHV. It is therefore of interest that the spontaneous firing rate of neurons in the hyperstriatum accessorium is significantly higher than that of neurons in IMHV (Payne and Horn, 1984).

\section{References}

Aggleton, J. P., and M. Mishkin (1983a) Visual recognition impairment following medial thalamic lesions in monkeys. Neuropsychologia 21: 189 197 
Aggleton, J. P., and M. Mishkin (1983b) Memory impairments following restricted medial thalamic lesions in monkeys. Exp. Brain Res. 52: 199 209.

Andrew, R. J., and A. Brennan (1983) The lateralization of fear behaviour in the male domestic chick: A developmental study. Anim. Behav. 31: 11661176.

Bateson, P. (1979) Brief exposure to a novel stimulus during imprinting in chicks and its influence on subsequent preferences. Anim. Learning Behav. 7: 259-262.

Bateson, P. P. G., and J. B. Jaeckel (1974) Imprinting: Correlations between activities of chicks during training and testing. Anim. Behav. 22: 899-906.

Bateson, P. P. G., and $\wedge$. ^. P. Wainwright (1972) The effects of prior exposure to light on the imprinting process in domestic chicks. Behaviour 42: $279-290$

Bateson, P. P. G., S. P. R. Rose, and G. Hom (1973) Imprinting: Lasting effects on uracil incorporation into chick brain. Science 181: $576-578$

Bateson, P. P. G., G. Horn, and S. P. R. Rose (1975) Imprinting: Correlations between behaviour and incorporation of $1^{14} \mathrm{C}$ ] uracil into chick brain. Brain Res. 84: 207-220.

Bradley, P. (1985) Development of two regions of the chick telencephalon Dev. Brain Res., 20: 83-88.

Bradley, P., and G. Horn (1979) Neuronal plasticity in the chick brain Morphological effects of visual experience on neurones in hyperstriatum accessorium. Brain Res. 162: 148-153.

Bradley, P., G. Horn, and P. P. G. Bateson (1979) Morphological correlates of imprinting in the chick brain. Neurosci. Lett. Suppl. 3: 84.

Bradley, P., G. Horn, and P. Bateson (1981) Imprinting: An electron microscopic study of chick hyperstriatum ventrale. Exp. Brain Res. 41: 115 120.

Brown, M. W., and G. Horn (1979) Neuronal plasticity in the chick brain Electrophysiological effects of visual experience on hyperstriatal neurones. Brain Res. 162: 142-147

Chang, H. T. (1952) Cortical neurons with particular reference to the apical dendrites. Cold Spring Harbor Symp. Quant. Biol. 17: 189-202.

Cherfas. J. J. (1978) Simultaneous colour discrimination in chicks is improved by brief exposure to light. Anim. Behav. 26: 1-5.

Cipolla-Neto, J., G. Horn and B. J. McCabe (1982) Hemispheric asymmetry and imprinting; the effect of sequential lesions to the hyperstriatum ventrale. Exp. Brain Res. 48: 22-27

Cochran, W. G., and G. M. Cox (1957) Experimental Designs, Fd. 2, pp 387-388, John Wiley \& Sons, Inc., New York.

Cohen, M. W. (1980) Development of an amphibian neuromuscular junction in vivo and in culture. J. Exp. Biol. 89: 13-56

Colonnier, M., and C. Beaulieu (1985) An empirical assessment of stereological formulae applied to the counting of synaptic discs in the cerebral cortex. J. Comp. Neurol. 231: 175-179.

Corner, M. A., H. J. Romijn, and A. P. J. Richter (1977) Synaptogenesis in the cerebral hemisphere (accessory hyperstriatum) of the chick embryo. Neurosci. Lett. 4: 15-19.

Davies, D. C., G. Horn, and B. J. McCabe (1985) Noradrenaline and learning The effects of the noradrenergic neurotoxin DSP4 on imprinting in the domestic chick. Behav. Neurosci. 99: 652-660.

Eccles, J. C. (1964) The Physiology of Synapses, Springer-Verlag, Berlin.

Gaffan, D. (1974) Recognition impaired and association intact in the memory of monkeys after transection of the fornix. J. Comp. Physiol. Psychol. 86 1100-1109.

Gottlieb, G., and M. L. Simner (1969) Auditory versus visual flicker in directing the approach response of domestic chicks. J. Comp. Physiol. Psychol. 67: $58-63$

Gray, E. G. (1959) Axo-somatic and axo-dendritic synapses of the cerebral cortex: An electron microscope study. J. Anat. 93: 420-433.

Hebb, D. O. (1949) The Organisation of Behavior, John Wiley \& Sons, Inc., New York.

Horn, G. (1962) Some neural correlates of perception. In Viewpoints in Biology, J. D. Carthy and C. L. Duddington, eds., Vol. 1, pp. 242-285, Butterworths, London.

Horn, G. (1981) Neural mechanisms of learning: An analysis of imprinting in the domestic chick. Proc. R. Soc. Lond. (Biol.) 213: 101-137.

Horn, G. (1985) Memory, Imprinting and the Brain, Clarendon Press, Oxford

Horn, G., and B. J. McCabe (1984) Predispositions and preferences. Effects on imprinting of lesions to the chick brain. Anim. Behav. 32: 288-292.

Horn, G., S. P. R. Rose and P. P. G. Bateson (1973) Experience and plasticity in the central nervous system. Science 181: 506-514.

Horn, G., B. J. McCabc, and P. P. G. Bateson (1979) An autoradiographic study of the chick brain after imprinting. Brain Res. 168: 361-373.
Horn, G., B. J. McCabe, and J. Cipolla-Neto (1983) Imprinting in the domestic chick: The role of each side of the hyperstriatum ventrale in acquisition and retention. Exp. Brain Res. 53: 91-98.

Howard, K. J., L. J. Rogers, and A. L. A. Boura (1980) Functional lateralisation of the chick forebrain revealed by use of intracranial glutamate. Brain Res. 188: 369-382

Hunt, S. P., and K. E. Webster (1972) Thalamo-hyperstriate interrelations in the pigeon. Brain Res. 44: 647-651.

Jacob, M., and T. L. Lentz (1979) Localization of acetylcholine receptors by means of horse-radish peroxidase- $\alpha$-bungarotoxin during formation and development of the neuromuscular junction in the chick embryo. J. Cell Biol. 82: 195-211.

James, N. T. (1977). Stereology. In Analytical and Quantitative Methods in Microscopy, G. A. Meek and H. Y. Elder, eds., pp. 9-28, Cambridge University Press, Cambridge, England.

Johnson, M., and G. Horn (1985) Dissociation of recognition memory and associative learning by a restricted lesion of the chick forebrain. Neuropsychologia, in press

Karten, H. J., W. Hodos, W. J. H. Nauta, and A. M. Revzin (1973) Neural connections of the "visual Wulst" of the avian telencephalon. Experimental studies in the pigeon (Columba livia) and owl (Speotyto cunicularia). J. Comp. Neurol. 150: 253-278.

Koch, C., T. Poggio, and V. Torre (1982) Retinal ganglion cells: A functional interpretation of dendritic morphology. Philos. Trans. R. Soc. Lond. (Biol.) 298: $227-264$

Kohsaka, S., K. Takamatsu, E. Aoki, and Y. Tsukada (1979) Metabolic mapping of chick brain after imprinting using $\left[{ }^{14} \mathrm{C}\right] 2$-deoxyglucose technique. Brain Res. 172: 539-544.

Konorski, J. (1948) Conditioned Reflexes and Neuron Organisation, Cambridge University Press, London.

Kossut, M., and S. P. R. Rose (1984) Differential 2-deoxyglucose uptake into chick brain structures during passive avoidance training. Neuroscience 12: $971-977$

McCabe, B. J., G. Horn and P. P. G. Bateson (1981) Effects of restricted lesions of the chick forebrain on the acquisition of filial preferences during imprinting. Brain Res. 205: 29-37.

McCabe, B. J., J. Cipolla-Neto, G. Horn, and P. Bateson (1982) Amnesic effects of bilateral lesions placed in the hyperstriatum ventrale of the chick after imprinting. Exp. Brain Res. 48: 13-21.

Mahut, $H$. (1985) Associative learning spared, memory not spared, after early hippocampal resections in the monkey. In Brain Plasticity, Learning and Memory, B. E. Will, P. Schmitt, and J. C. Dalrymple-Alford, eds., Plenum Pross, Now York, in pross.

Mayhew, T. M. (1979) Stereological approach to the study of synapse morphometry with particular regard to estimating number in a volume and on a surface. J. Neurocytol. 8: 121-138.

Miceli, D., J. Peyrichoux, and J. Reperant (1975) The retino-thalamo-hyperstriatal pathway in the pigeon (Columba livia). Brain Res. 100: 125131.

Miceli, D., H. Gioanni, J. Reperant, and J. Peyrichoux (1979) The avian visual Wulst. An electrophysiological study of the functional properties of single neurons. In Neural Mechanisms of Behavior in the Pigeon, A. M. Granda and J. H. Maxwell, eds., pp. 223-254, Plenum Press, New York.

Nottebohm, F. (1980) Rrain pathways for vocal learning in birds: a review of the first ten years. Prog. Psychobiol. Physiol. Psychol. 9. 85-124.

Payne, J. K., and G. Horn (1982) Differential effects of exposure to an imprinting stimulus on 'spontaneous' neuronal activity in two regions of the chick brain. Brain Res. 232: 191-193.

Payne, J. K., and G. Horn (1984) Long-term consequences of exposure to an imprinting stimulus on 'spontaneous' impulse activily in lle chick brair. Behav. Brain Res, 13: 155-162.

Payne, J. K., G. Horn, and M. W. Brown (1984) Modifiability of responsiveness in a visual projection area of the chick brain: Visual experience is only one of several factors involved. Behav. Brain Res. 13: 163-172.

Rall, W. (1974) Dendritic spines, synaptic potency and neuronal plasticity. In Cellular Mechanisms Subserving Changes in Neuronal Activity, C. D. Woody, K. A. Brown, T. J. Crow, and J. D. Knispel, eds., pp. 13-21, Brain Information Service, University of California, Los Angeles.

Rall, W., and J. Rinzel (1971) Dendritic spines and synaptic potency explored theoretically. Proc. Int. Congr. Physiol. Sci. 9: 466.

Ramón y Cajal, S. (1911) Histologie du Systeme Nerveux de l'Homme et des Vertébrés, Vol. 2, Maloine, Paris. (Republished 1955 as Histologie du Systeme Nerveux, Instituto Ramón y Cajal, Madrid.)

Rostas, J. A. P., V. A. Brent, and Güldner F. H. (1984) The maturation of post-synaptic densities in chicken forebrain. Neurosci. Lett. 45: 297-304. 
Simner, M. L. (1973) The development of visual flicker rate preference in the newly hatched chick. Dev. Psycholobiol. 6: 377-384.

Sluckin, W. (1972) Imprinting and Early Learning, Methuen, London.

Stewart, M. G., S. P. R. Rose, T. S. King, P. L. A. Gabbott, and R. Bourne (1984) Hemispheric asymmetry of synapses in chick medial hyperstriatum ventrale following passive avoidance training: A stereological investigation. Dev. Brain Res. 12: 261-269.

Takamatsu, K., and Y. Tsukada (1985). Neurobiological basis of imprinting in chick and duckling. In Perspective on Neuroscience from Molecule to Mind, Y. Tsukada, ed., pp. 187-206, Springer Verlag, Berlin

Tanzi, E. (1893) I fatti e le induzioni nell' odierna istologia del sistema nervoso. Riv. Sper. Freniat. Med I eg Alien. Ment 19:419-472

Weibel, E. R. (1969) Stereological principles for morphometry in electron microscopic cytology. Int. Rev. Cytol. 26: 235-302.
Weibel, E. R. (1979) Stereological Methods. Vol. 1: Practical Methods for Biological Morphometry, Academic Press, Inc., New York.

Weibel, E. R., and R. P. Bolender (1973) Stereological techniques in electron microscopic morphometry. In Principles and Techniques of Electron Microscopy. Biological Applications, M. A. Hayat, ed., Vol. 3. pp. 237-296. Von Reinhold, London.

Weiskrantz, L. (1982) Comparative aspects of studies of amnesia. Philos. Trans. R. Soc. Lond. (Biol.) 298: 97-109.

Zangwill, O. L. (1983) Disorders of memory. In Handhook of Psychiatry. Vol 1: General Psychopathology, M. Shepherd and O. L. Zangwill, eds., pp. 97-113, Cambridge University Press, Cambridge, England.

Zola-Morgan, S., and L. R. Squire (1981) Preserved learning in monkeys with medial temporal lesions: Sparing of motor and cognitive skills. J. Neurosci. 4: 1072-1085 